\title{
Our Contribution to the NASA RASSOR Bucket Drum Design Challenge
}

\author{
Stephan Weißenböck ${ }^{1}$ and Eric Fimbinger ${ }^{2}$ \\ ${ }^{1}$ Mechanical Engineering studies programme, Montanuniversität Leoben, Leoben, Austria \\ ${ }^{2}$ Chair of Mining Engineering - Conveying Technology and Design Methods, Montanuniversität Leoben, Leoben, \\ Austria
}

Received December 2, 2020; accepted December 17, 2020; published online February 5, 2021

\begin{abstract}
NASA's Artemis program aims to return humans to the Moon sustainably and efficiently by using new and improved technology, which is based on the concept of generating products with local materials, a practice called In Situ Resource Utilization (ISRU). Regolith excavation is the fundamental step in the ISRU chain to produce local commodities, such as propellants and breathing air, and to pursue construction operations. NASA is currently working on the Regolith Advanced Surface Systems Operations Robot (RASSOR), the key technology to enable extraterrestrial mining. The robot uses counterrotating bucket drums that capture regolith and keep it from falling out. NASA reached out to the public via GrabCAD to improve the robot's design and chose five concepts, which will be tested and further improved. A team of three students from the University of Leoben (Dominik Höber, Andreas Taschner, and Stephan Weißenböck) took part in the challenge set by NASA and shared their ideas and concepts. They used this opportunity to implement their acquired knowledge from their studies and were also supported by a researcher from the Chair of Mining Engineering of the University of Leoben-Eric Fimbinger. The final design consists of three significant elements that were fused to increase efficiency: An outer helix, a spiral tunnel, and an inner helix. These three important components make up the concept which impressed the jury and reached fourth place out of approx. 350 entries. Due to the success of the project as well as the aroused interest amongst the students, further research projects were initialised as follow-ups, dealing with the topic of extraterrestrial mining. One is a research and development study covered by two master's theses about excavation and conveying concepts on the Moon (see the article by Höber, Taschner and Fimbinger in this issue). The other one is in the form of a bachelor's thesis to compare and analyse
\end{abstract}

S. Weißenböck ( $\square)$

Mechanical Engineering studies programme,

Montanuniversität Leoben,

Leoben, Austria

stephan.weissenboeck@stud.unileoben.ac.at chosen concepts from the design challenge in a numerical simulation environment with equal conditions to allow virtual testing of those chosen designs.

Keywords: NASA, RASSOR, ISRU, Bucket drum, Concepts, Design, Moon, Space

\section{Unser Beitrag zur NASA RASSOR Bucket Drum Design Challenge}

Zusammenfassung: Das Ziel des neuen Raumfahrtprojektes der NASA namens "Artemis" besteht darin, für einen längeren Zeitraum und effizient auf den Mond zurückzukehren. Dabei wird auf neue und verbesserte Technologie gesetzt, welche unter anderem auf dem Konzept der In Situ Resource Utilization (ISRU) basiert, bei dem es gilt Produkte mit lokalen Materialien vor Ort zu erzeugen. Dabei spielt der Abbau von Mondgestein, auch Regolith genannt, die entscheidende Rolle in der ISRU-Kette um lokale Güter, wie Treibstoff oder Atemluft zu entwickeln und zukünftigen Bauarbeiten nachzugehen. NASA arbeitet derzeit an der tragenden Schnittstelle, um das neue Konzept zu verwirklichen, dem "Regolith Advanced Surface Systems Operations Robot" (RASSOR). Der Roboter benutzt in seiner Arbeitsweise entgegensetzt-rotierende Trommeln, um Regolith aufzusammeln, zu speichern und an einem gewünschten Ort abzugeben. NASA entwickelte eine öffentlich zugängliche Challenge, bei der es galt das Design der Trommeln zu verbessern und kührte im Zuge dieser Herausforderung fünf herausragende Konzepte, welche derzeit genauer getestet und analysiert werden. Ein Team, bestehend aus drei Studierenden der Montanuniversität Leoben (Dominik Höber, Andreas Taschner und Stephan Weißenböck) stellten sich dieser Herausforderung und reichten ihr Konzept ein. Dabei nutzten sie diese Chance, das erlernte Wissen aus ihrem Studium in die Praxis umzusetzen und wurden zudem unterstützt von einem wissenschaftlichen Mitarbeiter des Lehrstuhls für Bergbaukunde der Montanuniversität Leoben, aus dem Fachbereich der Fördertechnik und Konstruk- 


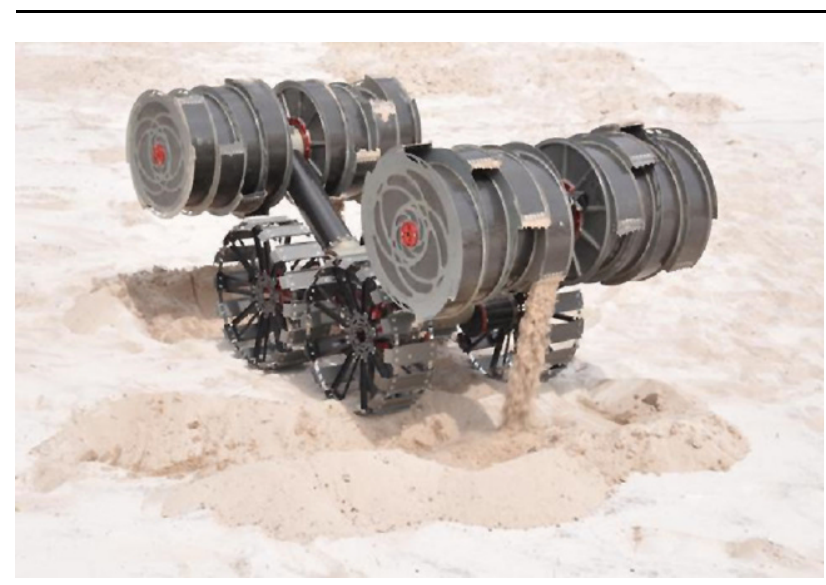

Fig. 1: NASA RASSOR [3]

tionslehre, Eric Fimbinger. Das finale Trommeldesign setzt sich aus drei wesentlichen Elementen zusammen: Einer äußeren Helix, einer spiralförmigen Umleitung (Tunnel) und einer inneren Helix. Diese drei wichtigen Komponenten ergeben das Konzept, welche die Jury überzeugen konnte und den vierten Platz von fast 350 Einreichungen sicherte. Aufgrund des Erfolges des Projekts und des erweckten Interesses der Studenten wurden weiter Forschungsprojekte initialisiert, welche sich auf den extraterrestrischen Abbau konzentrieren. Ein solches Projekt, bearbeitet in zwei Masterarbeiten, behandelt den Rohstoffabbau und die Fördertechnik am Mond. Ein weiteres wurde in Form einer Bachelorarbeit ausgelegt, welche sich mit ausgewählten Trommelkonzepten der Challenge beschäftigt und diese in einer numerischen Simulation mit gleichen Umgebungsbedingungen vergleicht und analysiert.

Schlüsselwörter: NASA, RASSOR, ISRU, Abbautrommel, Konzepte, Design, Mond, Raumfahrt

\section{Introduction}

NASA's Artemis program not only aims to send the first woman and the next man back to the Moon by 2024 but also plans to enable a sustainable space base by 2028 [1].
The long-term goal is to take the next big step in space travel: Send humans to Mars and become an interplanetary species. To accomplish their objective, new technology and approaches have to be tested on the Moon to prepare for the much more difficult and precarious mission to Mars.

As part of the Artemis program, humans will live on the lunar surface for extended periods of time on a sustainable settlement based on the materials that are available on the Moon. The practice of generating products by using local materials is called In Situ Resource Utilization (ISRU), and it will become increasingly important the further we go into deep space [2]. The first step to generate products that are needed for a permanent base is to collect regolith (asteroid soil). NASA already has plans for an excavation robot, which is called the Regolith Advanced Surface Systems Operations Robot (RASSOR) as seen in Fig. 1.

There are many factors that affect the efficiency of the RASSOR. First, the machine has to be small and lightweight, as space transportation costs are extremely high, at around $8800 €$ per kilogram [4] (depending on the rocket system used). Considering the low gravitational forces on the Moon, the relatively light structure cannot operate with traditional excavation methods that are used on Earth: By using a drill or a shovel, the robot would push itself away from the surface. Therefore, the RASSOR is designed to use a different approach to excavation. The robot's main parts are the four drums mounted to the chassis, as seen in Fig. 1, which are used to collect, store, and discharge regolith. By counterrotating the drums, the robot generates horizontal forces, which equalise themselves because of the opposite spin and minimal vertical forces, as shown in Fig. 2. As a result, the system is not mainly reliant on weight or traction and can be applied in environments with low gravity. Due to the created forces, the scoops on the drums "cut" loose areas of regolith and guide this bulk material inside, where it is prevented from falling out by specifically designed mechanisms and baffles. The robot can now raise its arms and transport the collected regolith to a desired spot where it can discharge the material by simply reversing the rotation of the drums. The design of the drums is not yet finished, and NASA is still trying to improve the robot, so they reached out to the public to gather different variations and approaches to their design.

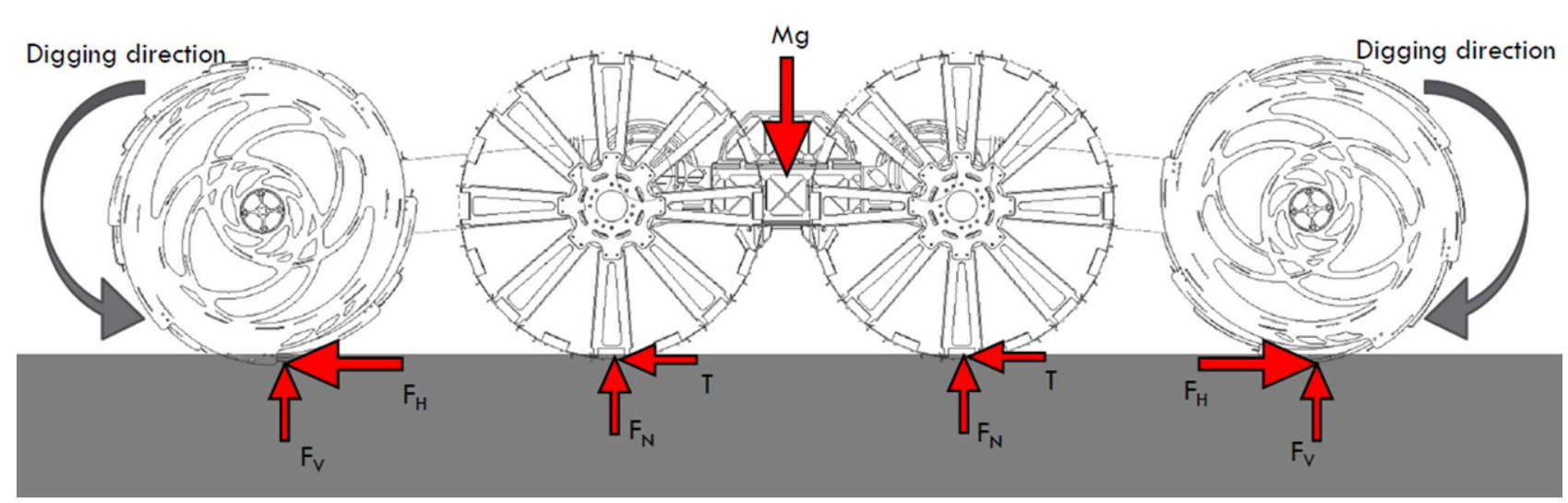

Fig. 2: Generated forces [5] 


\section{The Challenge}

NASA used GrabCAD, a CAD community website, to host their challenge of designing a new concept to increase the efficiency of the robot's drums [6]. GrabCAD is an online community portal for professional designers, engineers, manufacturers, and students where they can share their ideas and upload their projects. In March 2020, NASA created the "NASA Regolith Advanced Surface Systems Operations Robot (RASSOR) Bucket Drum Design Challenge" with the task to revise the current design of the drums to "provide the maximum amount of regolith extraction and retention while remaining free of obstructions during loading and unloading" [6]. In addition to that, the following requirements had to be met:

- Maximum total width of scoops engaged at any given time: $175 \mathrm{~mm}$

- Maximum bucket drum mass: $5 \mathrm{~kg}$

- Maximum bucket drum diameter: $450 \mathrm{~mm}$

- Maximum bucket drum length: $360 \mathrm{~mm}$

- A minimum volume of regolith captured: 17.61

The challenge appealed to the Chair of Mining Engineering, where researchers were already working on unconventional mining/conveying technologies and were also connected to projects such as related to this subject-and which were also interested in interconnecting excavation with space sciences. In this regard, two researchers (Eric Fimbinger and Philipp Hartlieb) are also members of an international community called SONet (The Sustainable Offworld Network) consisting of academic professionals with wide-ranging expertise on broad topics with the goal of developing a sustainable extraterrestrial human settlement with focus on Moon and Mars [7].

In the end, three motivated mechanical engineering students (Dominik Höber, Andreas Taschner, and Stephan Weißenböck), supported by Eric Fimbinger, volunteered to take part in this challenge.

\section{Design Details}

With the implementation of a helical blade on the outside drum shell, the design provides the ability to collect regolith throughout the entire width of the drum. At the end of the outer helix, a scoop picks up the loose regolith (as bulk material), which is also pushed in this area of the scoop by the outer helix, afterwards transported into the inside of the drum. Once inside, the material is further transported by an inner helix to allow a high filling capacity. The three essential components are highlighted in Fig. 3.

In total, two outer helixes, two scoops, and two inner helixes are used on one drum (see Fig. 4). This system not only increases the fill ratio but also provides more stability to the drum in the operating state because of its axial symmetry. The fill ratio is further improved by a specific spiral surface (resulting in a spiral tunnel), right after the scoops, which releases the regolith into the helixes and prevents collected material from falling out. As visible in Fig. 5, a system that

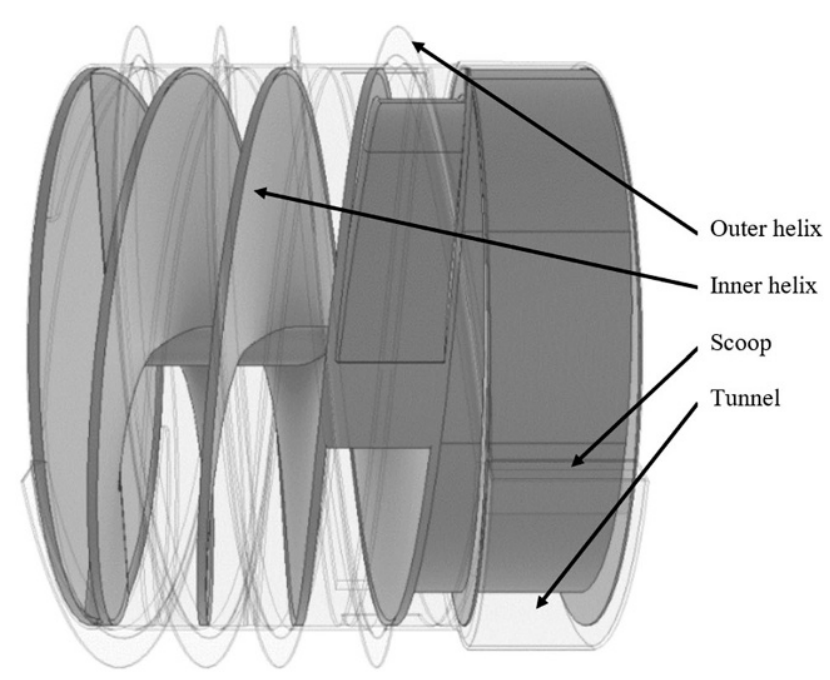

Fig. 3: Transparent illustration of the drum

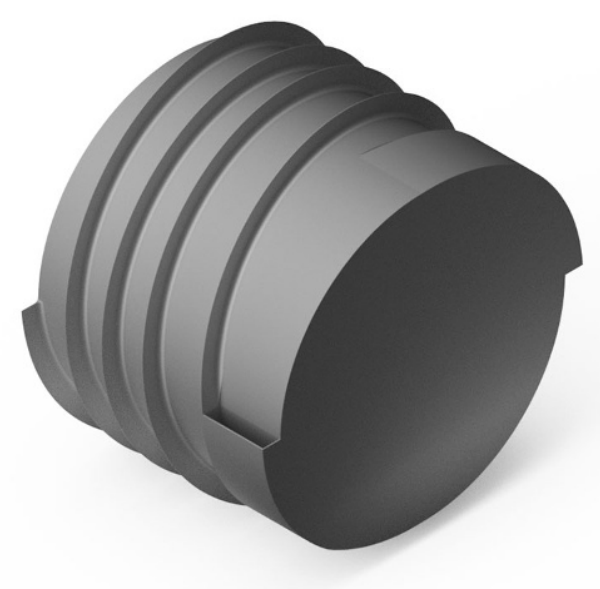

Fig. 4: Right-sided view of the drum

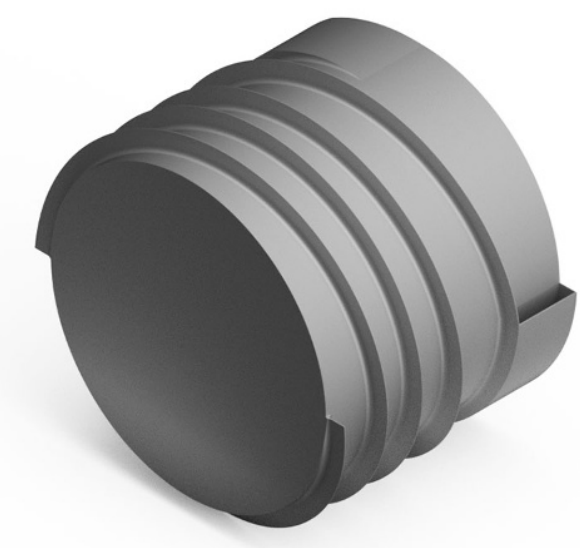

Fig. 5: Left-sided view of the drum 

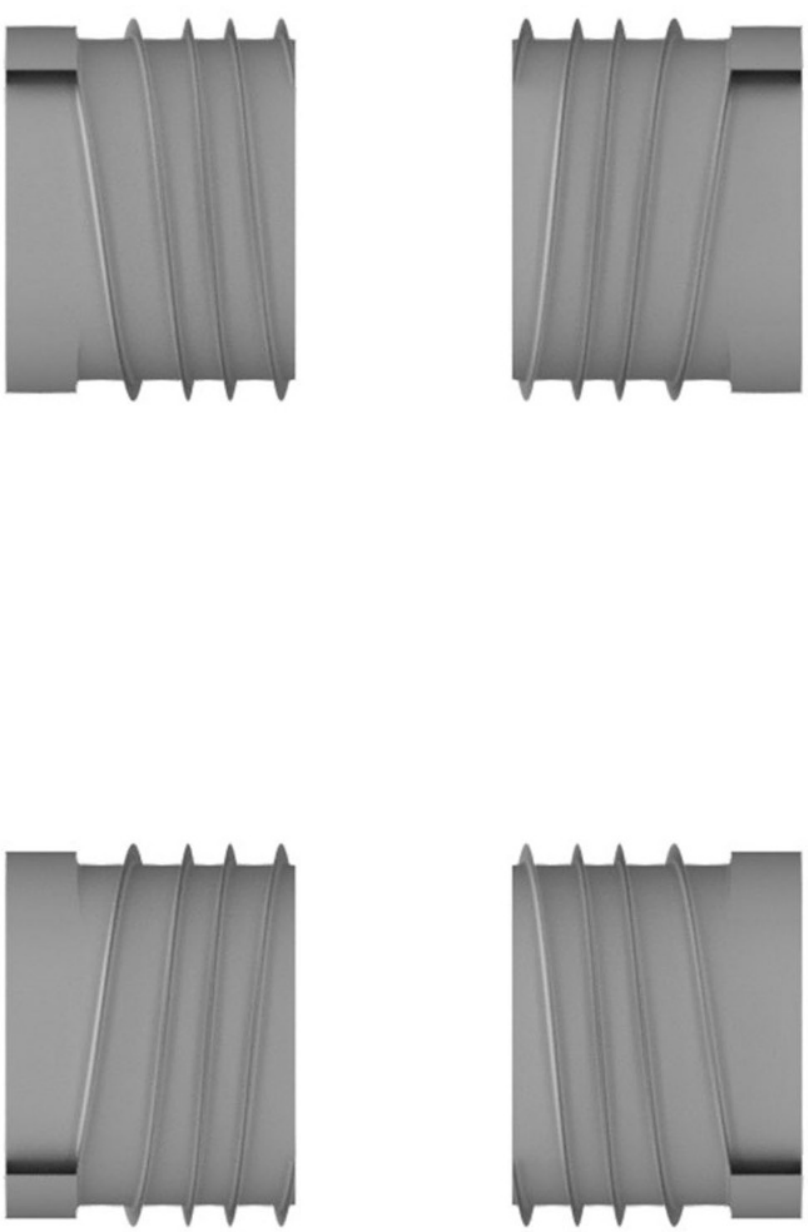

Fig. 6: Placement of the drums on the robot, seen from above

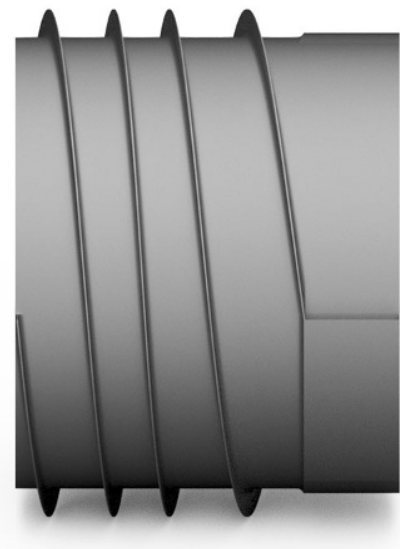

Fig. 7: Helical blades, scoop visible on the right

uses two scoops instead of one was chosen, which enables the drum to collect regolith faster and provides more stability to the system with the established symmetry.

In addition to that, such a drum only consists of one part and can be produced using 3D-manufacturing. With a weight of $4.93 \mathrm{~kg}$ and a fill ratio of about approximately $75 \%$ (and maybe even higher), the design optimises the available drum space which can be used to store regolith while maintaining a low part weight. The simplicity of the design and the avoidance of moving mechanical parts are essential for the longevity of the robot, especially in space applications.

So, in general, three system components are implemented in this bucket drum design that account for its advantages: The outer double-helix, the scoops with the spiral tunnels, and finally the inner double-helix. Details of these three components are described further below.

Regarding the overall arrangement of four drums on the RASSOR, as according to Fig. 1 two sets of drums are mirrored on each side of the robot, as illustrated in Fig. 6, to ensure symmetry. This arrangement cancels the axial forces that act on the drums during operation. The positions of the scoops are chosen to be situated on the outside "edges" of the robot (see Fig. 6), for the reason that any material that does not fit into the drums anymore is pushed out of the robot's way, instead of creating a pile in front of the robot, which would be the result if the scoops were situated on the inside.

\subsection{Outer Double-helix}

Due to the rotation of the drum, the blades of the outer double-helix, visible in Fig. 7, loosen the regolith and transfer it to one of the two scoops. Unsteady ground does not influence the functionality. This system enables the ability to collect regolith throughout the entire width of the drum while maintaining a relatively large volume to store the material inside of the drum. If the rotation of the drum is reversed (unloading operation state), the blades do not have any function, as this activity takes place when the drum is raised off the ground.

\subsection{Scoops and Spiral Tunnels}

After the outer double-helix, the loosened regolith is collected by the scoops, which line up with the end of the outer helical blades (Fig. 8), guided along with spiral barriers (tunnels; see Fig. 9), and released into the helixes on the inside. This 180-degree spiral tunnel system prevents already collected regolith from falling out while the drum is in its collecting state and therefore increases the fill ratio significantly. When releasing the regolith, the spiral tunnels spin in the other direction and releases the material at the lowest point of the drum. The system is designed to provide a smooth path for the regolith for optimal material flow during filling as well as during unloading, where it is also designed with no cavities to ensure that no material is left behind in the drum.

\subsection{Inner Double-helix}

The inside of the drum contains another double helix, which guides the regolith away from the scoops and spirals into the backside of the drum, on the opposite side of the scoops. 


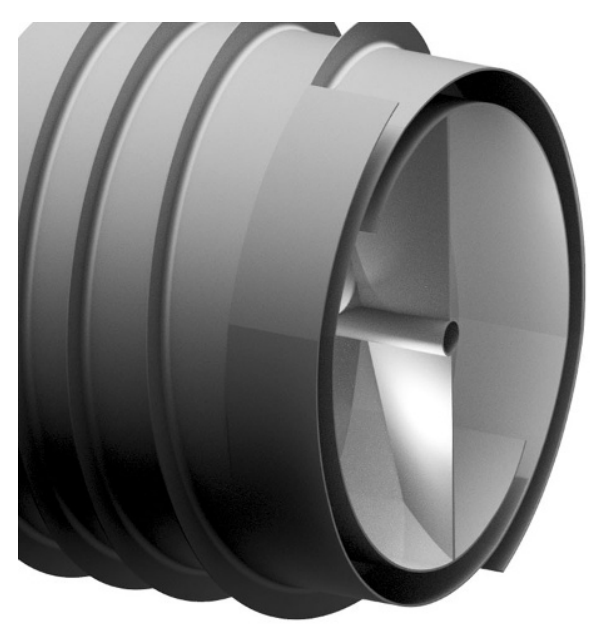

Fig. 8: Side view of the two spiral tunnels beginning at each scoop (without side cover at the scoop side)

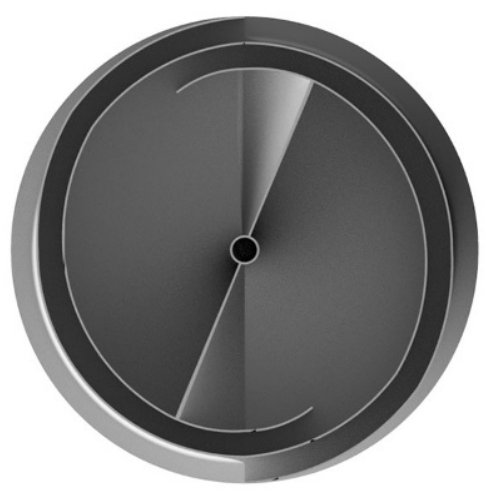

Fig. 9: Side view, showing the two opposite 180-degree spiral tunnels (without side cover at the scoop side)

Its direction is mirrored to the double-helix on the outside to ensure the material transport towards the other direction while the rotation of the drum stays the same. The centre axis prevents the material from falling into the other chamber. There are guiding barriers, which make sure that all collected regolith is inserted into the double-helix. Reaching the other end of the drum, the helixes are rounded down to avoid sharp edges in which the regolith can get stuck. If the rotation of the drum is reversed, the collected material is guided towards the spiral tunnels and is at the end released from the drum chamber through these tunnels. Fig. 10 and 11 both illustrate the inner double-helix.

\subsection{Advantages}

The outer double-helixes ensure that the whole area of the drum can collect regolith, provide stability because of its rotational symmetry, and are uninfluenced by uneven ground conditions. The scoops and the spiral tunnels have a major impact on the fill ratio of the system and make sure that the inner chamber of the drum (with the double-helixes)

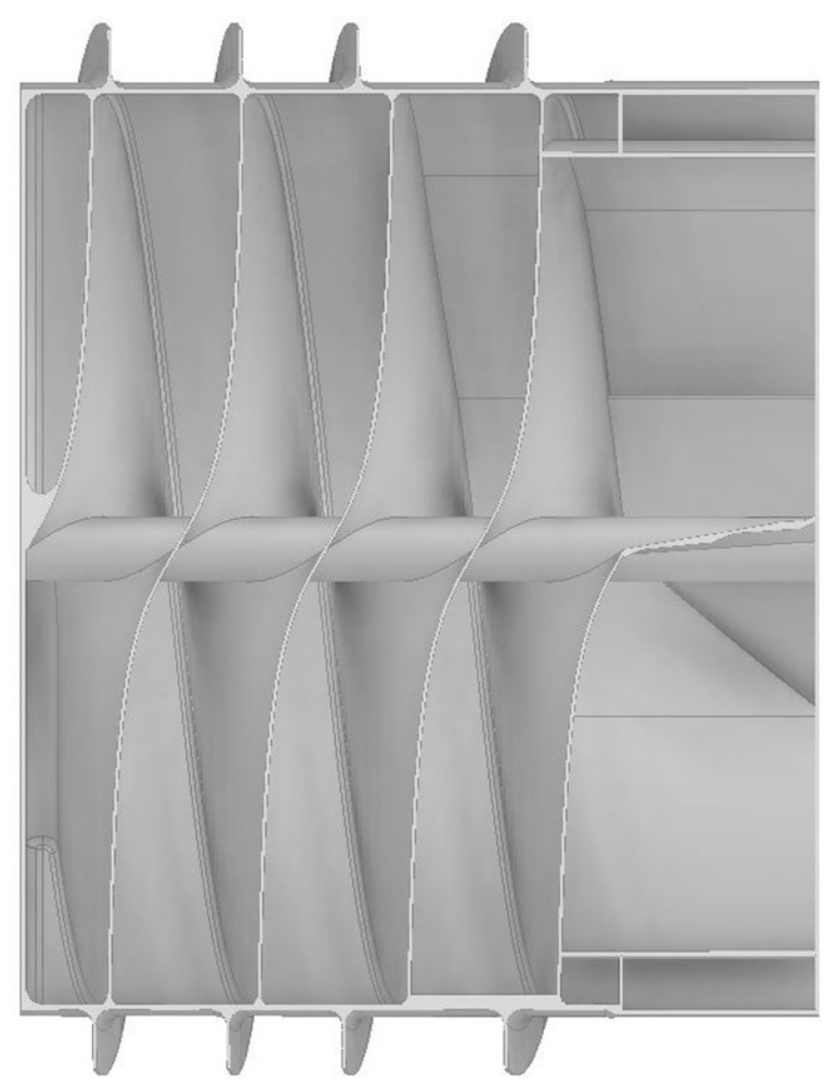

Fig. 10: Sectional view of the drum (scoops on the right)

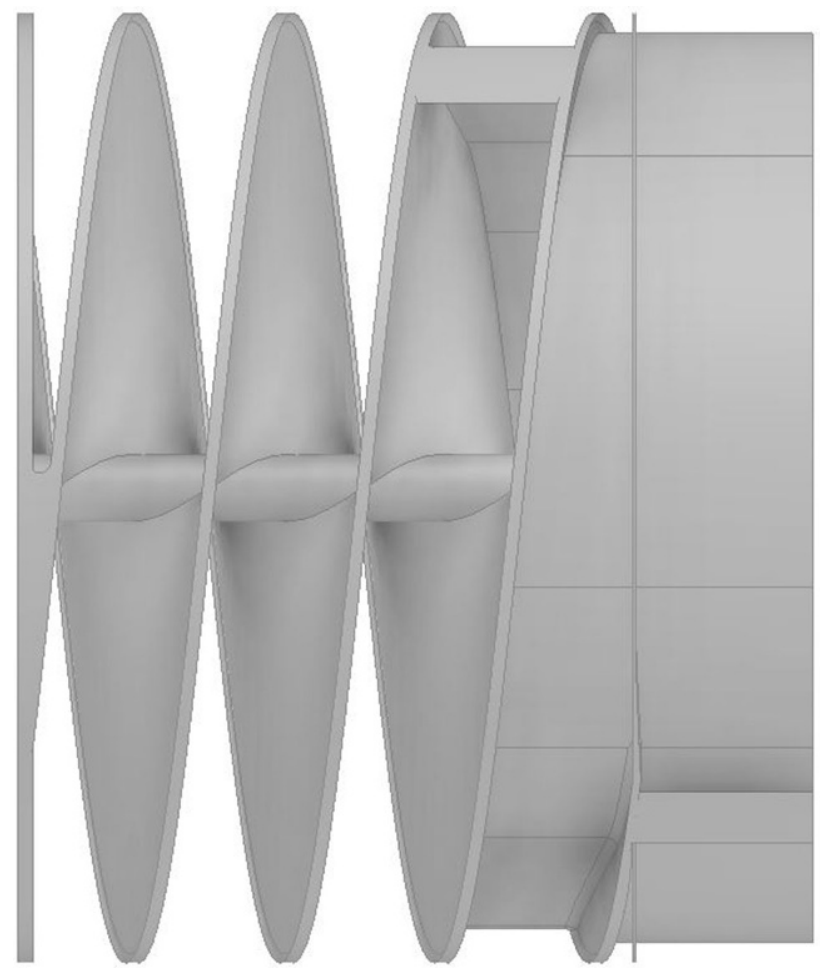

Fig. 11: Drum without cover and outer helixes; inner double helixes visible 


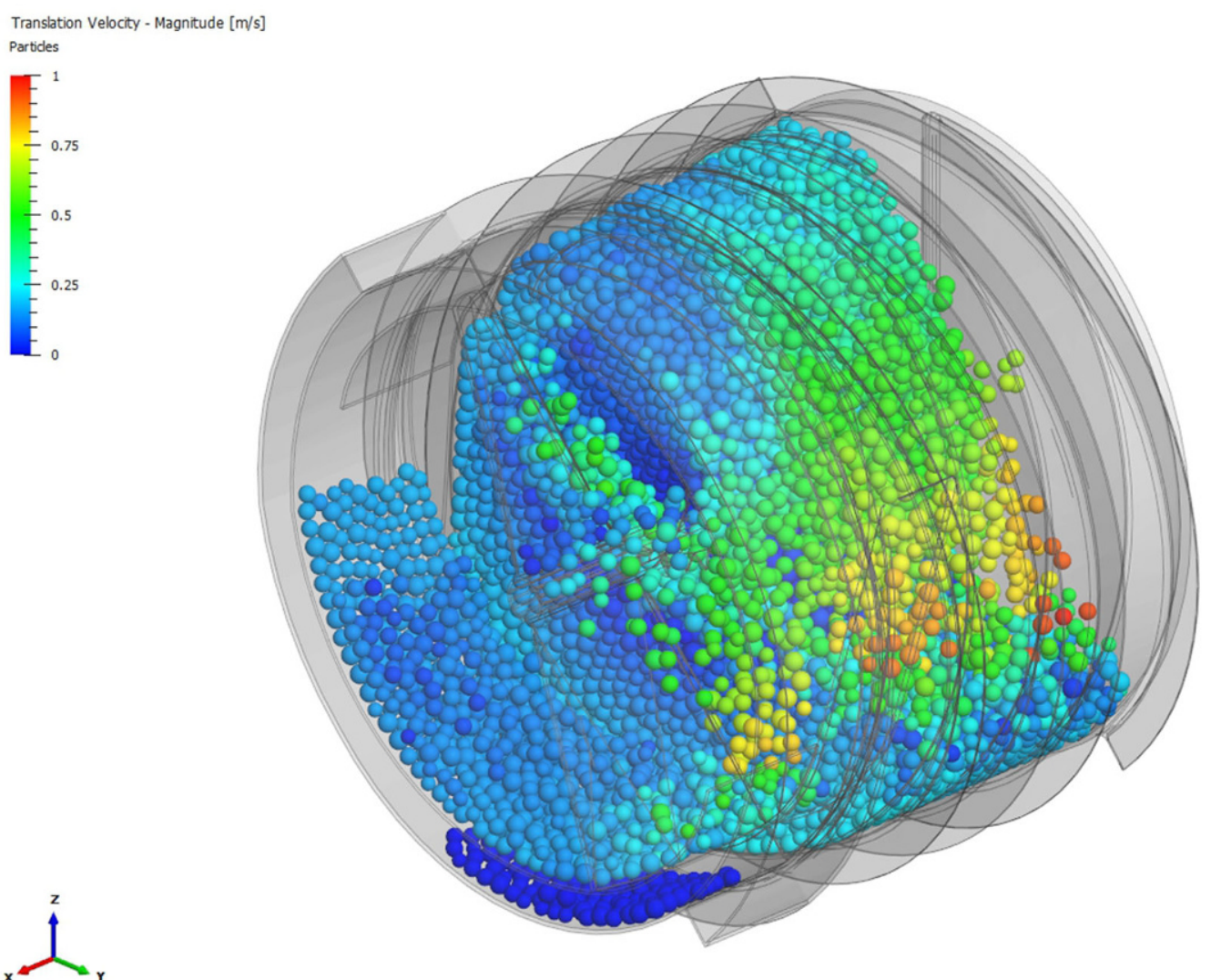

8. ThreeParticle
Academic

Translation Velocity - Magnitude [m/s]

Fig. 12: DEM simulation of the bucket drum while filling

Translation Velocity - Magnitude [m/s]

Partides
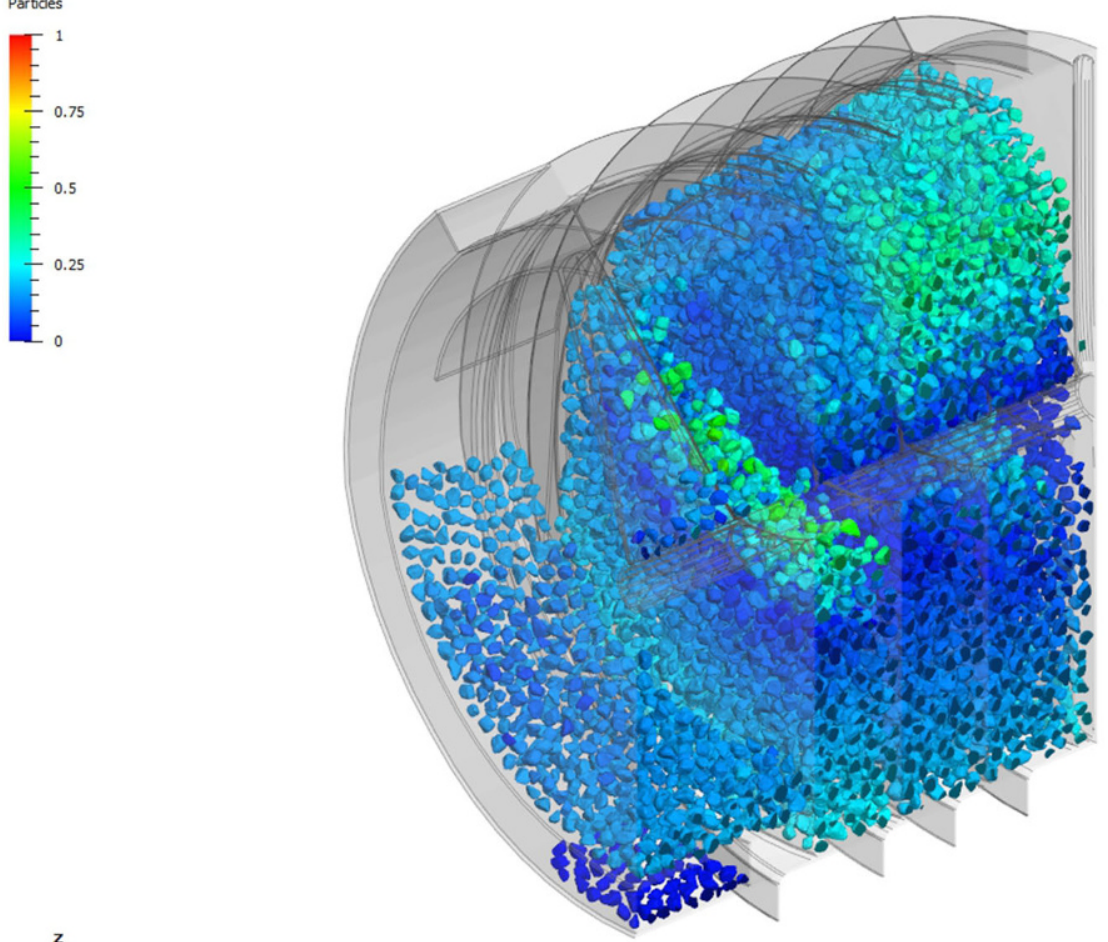

Academic

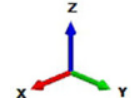

Fig. 13: Sectional view of the simulation 

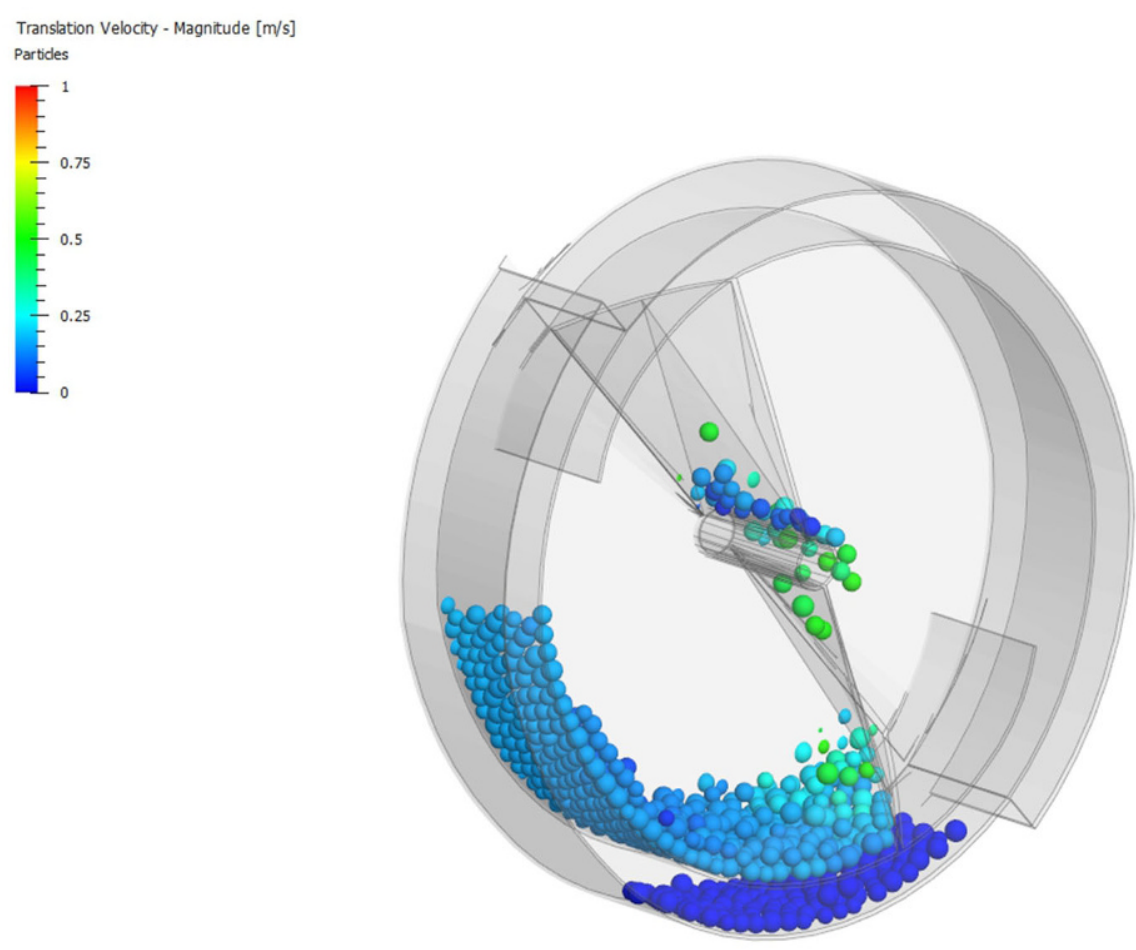<smiles>[Mg][Te]</smiles>

Fig. 14: The spiral tunnels transporting the material (DEM simulation)

can nearly be completely filled. Also, the collected material is prevented from falling out within one revolution due to the spiral tunnels connected to the double-helixes on the inside. Another advantage of this design is the fact that the scoops do not have to dig into the regolith as it is loosened and guided towards the scoops by the outer helixes as blades.

\subsection{Simulation}

A numerical simulation of the drum's operation was also performed, using the software "ThreeParticle/CAE" by Becker 3D. The goal of this DEM (Discrete Element Method) simulation was to analyse the filling and releasing behaviours of the drum and to provide information about the fill ratio with a revolution speed of $12 \mathrm{rpm}$. The fill ratio is dependant on the rotation speed and other factors that can be optimised in the simulation.

Fig. 12 shows the DEM simulation of the bucket drum, where regolith, in the form of discrete particles is inserted into the scoops. The movement of the collected regolith inside the drum is visualised in colour. Fig. 13 shows the results from the DEM simulation in a sectional view, and Fig. 14 shows the spiral tunnels in operation, which are described in Sect. 3.2.

\section{Short Outline of Other Design Concepts}

As mentioned initially, the main goal of creating a challenge that is open for the public is to gather a wide variety of new approaches. This variety can also be seen when analysing other concepts, such as the top five winner concepts.

One design concept, for example, includes a trap door which prevents the collected regolith from falling out, while still maintaining the possibility to open the door in the discharging state, which can be seen in Fig. 15. The disadvantage of these concepts is the use of moving parts, which increases the likelihood of malfunction and is responsible for decreasing the durability of the drums. On the other hand, this method allows to use less material and leads to a lighter

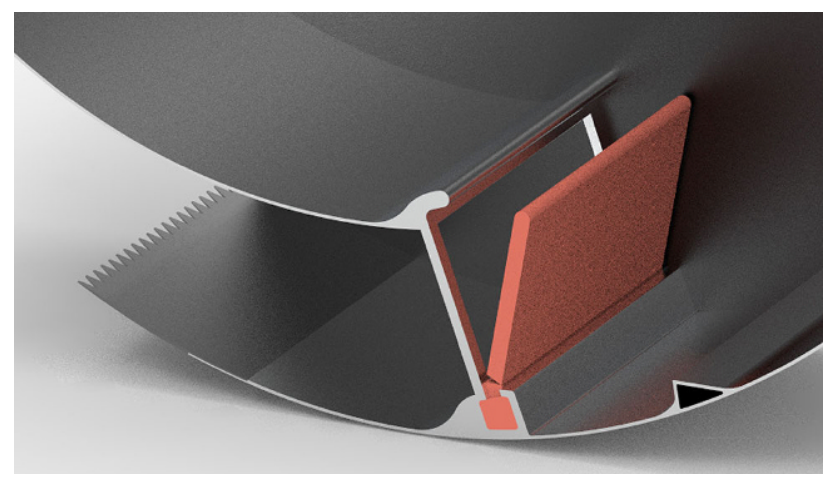

Fig. 15: Regolith trap door 


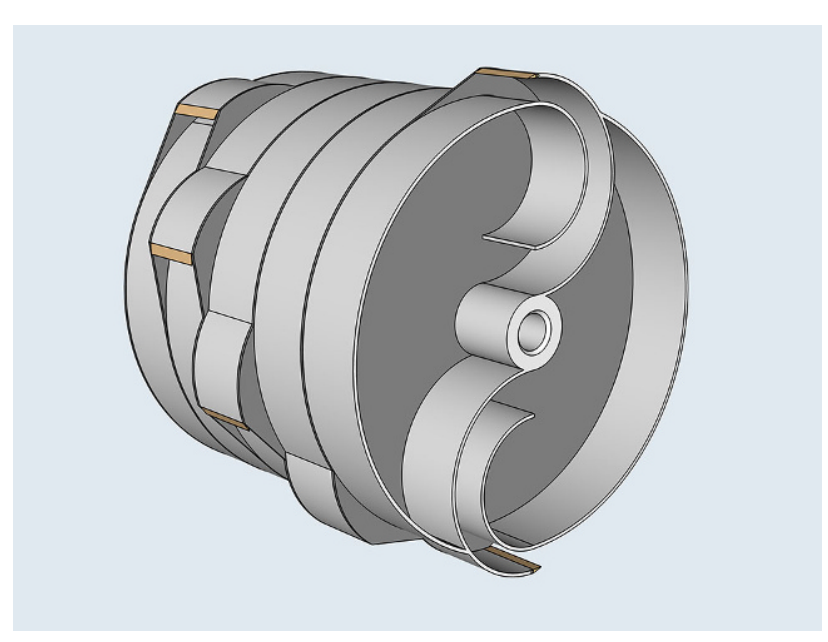

Fig. 16: Another form of spiral tunnels [9]

design with a high fill ratio close to $90 \%$, as stated by the designer [8]. While the presented design from above (described in Sect. 3) fuses the ideas of inner and outer helixes as well as spiral tunnels, some concepts used other variants of these systems consisting of more helixes or other forms/arrangements of tunnels, as shown in Fig. 16.

\section{Future Prospects}

There are lots of interesting designs for the bucket drum, and every one has its advantages and disadvantages. While the backgrounds of the participants of the challenge varied as much as their approaches to their designs, so did their simulations, analyses, and results. Each design stood out in its own chosen environment and under its individual operational conditions, but it was not possible to directly compare them based on the task of the challenge. Closer analyses may require a lot of testing and comparing work. Therefore, a project has been commenced to compare and analyse chosen concepts from the design challenge in a numerical simulation environment with equal conditions to allow virtual testing of a variety of chosen drum designs as a bachelor's thesis. As the general interest in the area of space technology grew amongst the students that participated in the challenge, two further master's theses were initiated that focus on the topic of extraterrestrial mining. Thereby, the possibilities and concepts for mining and conveying lunar soil on the Moon are covered.

NASA itself is in the phase of analysing the concepts of the challenge, with the possible outcome, that one of these bucket drum designs could once be used for a future mission to another planet and collect regolith, not in a simulated world, but in reality.

\subsection{Direct Links}

Challenge NASA Regolith Advanced Surface Systems Operations Robot (RASSOR) Bucket Drum Design Challenge | Engineering \& Design Challenges | GrabCAD

https://grabcad.com/challenges/nasa-regolith-advancedsurface-systems-operations-robot-rassor-bucket-drumdesign-challenge

Entry of Bucket Drum Double-Helix NASA Bucket Drum Double-Helix | 3D CAD Model Library | GrabCAD

https://grabcad.com/library/nasa-bucket-drum-doublehelix-1

DEM-Simulation Video RASSOR Bucket Drum Design Simulation-YouTube

https://youtu.be/i16OVS90WGs

Funding. Open access funding provided by Montanuniversität Leoben.

Open Access This article is licensed under a Creative Commons Attribution 4.0 International License, which permits use, sharing, adaptation, distribution and reproduction in any medium or format, as long as you give appropriate credit to the original author(s) and the source, provide a link to the Creative Commons licence, and indicate if changes were made. The images or other third party material in this article are included in the article's Creative Commons licence, unless indicated otherwise in a credit line to the material. If material is not included in the article's Creative Commons licence and your intended use is not permitted by statutory regulation or exceeds the permitted use, you will need to obtain permission directly from the copyright holder. To view a copy of this licence, visit http://creativecommons.org/licenses/by/4.0/.

\section{References}

1. NASA. 2020. NASA's Plan for Sustained Lunar Exploration and Development.

2. NASA: Overview: In-Situ Resource Utilization, https://www.nasa. gov/isru/overview (29.10.2020).

3. NASA: RASSOR, https://www.nasa.gov/sites/default/files/thumbnails/ image/medium_1_0.png (09.11.2020).

4. NASA: Regolith Advanced Surface Systems Operations Robot (RASSOR) Excavator, https://technology.nasa.gov/patent/KSCTOPS-7 (29.10.2020).

5. NASA: RASSOR Excavator for ISRU Lunar Mining, https://www. hou.usra.edu/meetings/lunarisru2019/presentations/5061_Schuler. pdf (09.11.2020).

6. NASA: NASA Regolith Advanced Surface Systems Operations Robot (RASSOR) Bucket Drum Design Challenge, https://grabcad. com/challenges/nasa-regolith-advanced-surface-systems-operationsrobot-rassor-bucket-drum-design-challenge (29.10.2020).

7. SONet: The Sustainable Offworld Network, https://sonet-hub.com/ (20.11.2020).

8. Caleb Clausing: Regolith Trap, https://grabcad.com/library/regolithtrap-3 (17.11.2020).

9. Michael, R: RASSOR Bucket Drum, https://grabcad.com/library/ rassor-bucket-drum-11 (25.11.2020).

Publisher's Note. Springer Nature remains neutral with regard to jurisdictional claims in published maps and institutional affiliations. 